\title{
Las ocupaciones laborales en función de los requisitos de competencias lingüísticas: una categorización mediante redes neuronales artificiales
}

\author{
M. Carme Molina-Cobo \\ mcarmen.molina@urv.cat \\ M. Teresa Sorrosal-Forradellas \\ mariateresa.sorrosal@urv.cat \\ Antoni Vidal-Suñé \\ antoni.vidal@urv.cat \\ Universitat Rovira i Virgili, Spain
}

Resumen: Este trabajo tiene como objetivo agrupar las distintas ocupaciones laborales en diversas categorías en función de la semejanza en los requisitos que presenta cada ocupación en cuanto a competencias lingüisticas. Para ello, se utilizan los datos para las ocupaciones definidas en la O'Net-SOC-2010 para EE.UU. en 2015. Se consideran tres clasificaciones, en función del nivel de desagregación que presentan los datos de O'Net. El análisis se efectúa mediante redes neuronales artificiales, en concreto, los mapas autoorganizativos de Kohonen (SOM). Se pretende así analizar si el nivel de desagregación de las ocupaciones influye en la clasificación de dichas ocupaciones en función del nivel requerido de competencias lingüisticas. La aportación que se reali$z a$ es novedosa, ya que, basta donde conocemos, no existe ningún trabajo previo que utilice los SOM para la clasificación de las ocupaciones laborales considerando las competencias lingüisticas requeridas. Dicho análisis puede ayudar a los investigadores sociales en el estudio del impacto e influencia que presentan los componentes lingüisticos del trabajo en la productividad laboral, la empleabilidad de los trabajadores, los resultados empresariales y la generación de ventajas competitivas basadas en el lenguaje, entre otras.

Palabras clave: competencias lingüisticas; ocupaciones laborales; mapas autoorganizativos. 


\begin{abstract}
The aim of this study is to classify different types of occupations according to similarities in their requirements with regard to language skills. To do so, we use data on these occupations from the O NET-SOC-2010 for the USA in 2015. Three classifications, depending on the level of disaggregation of the O'NET data, are considered. Our analysis is conducted using artificial neural networks - specifically, Kohonen's self-organizing maps (SOM) - to determine whether the level of disaggregation of the occupations influences their classification by the level of linguistic competence required. This is a novel contribution since, as far as we know, no previous study has used SOMs to classify occupations according to required language competence. Our analysis may help social researchers to study how the linguistic components of an occupation influence productivity, worker employability, business results, and the generation of competitive advantages based on language, etc.
\end{abstract}

Keywords: language skills; occupations; self-organizing maps. 


\section{Introducción}

La actividad económica ha sufrido cambios substanciales a lo largo de la segunda mitad del siglo xx y, aún con mayor intensidad, en los años transcurridos del siglo Xxi. Castells (2000) define este periodo como capitalismo informacional, mientras que Bueno (1998) habla de sociedad del conocimiento. En la sociedad de la información y del conocimiento el recurso más valioso es lo que los empleados y organizaciones saben y conocen; con lo que la generación de riqueza y el empleo procede cada vez más de las industrias basadas en las ideas o sector quinario (Recio, 2005), que se articula alrededor de todas aquellas actividades que se fundamentan en la creatividad, la experimentación, la innovación, la ciencia y el saber.

Esta Economía del Conocimiento afecta específicamente a los procesos de producción y gestión, con una constante y acelerada innovación tecnológica en un contexto de creciente globalización. Así, las actividades de producción, difusión y aplicación de la investigación, el desarrollo y la innovación cobran un peso creciente en los diferentes sectores de la economía. La competitividad empresarial se fundamenta en el contenido científico, tecnológico e innovador de los bienes y servicios que se producen. Según Bueno (1998), la sociedad del conocimiento se caracteriza por la aparición continua de nuevos saberes y el desarrollo permanente de las facultades intelectuales; donde adquieren primacía los conocimientos tácitos de los empleados, que requieren de unos procesos basados en la creación, en las ideas, en la abstracción y en la innovación. Estos conocimientos son de difícil transmisión y comunicación, dado que se basan en la experiencia y en el talento idiosincrásico, en el arte y en el "saber hacer" (Kim y Mauborgne, 1997). No obstante, para que sean "productivos", los empleados deben saber comunicarlos y transmitirlos; es decir, cada vez más, las competencias lingüísticas de los empleados son más esenciales para el éxito competitivo de las organizaciones.

Para Nonaka y Takeuchi (1995), son estos conocimientos los que posibilitan la generación y sostenibilidad de la ventaja competitiva de las empresas. Hoy en día, una empresa para ser competitiva debe crear, localizar, capturar, absorber y compartir, de manera eficaz, eficiente y efectiva, el conocimiento necesario para solucionar los problemas que se le presenten. Ello supone una Gestión del Conocimiento (Knowledge Management), que, para Bueno (2000), viene determinada por la gestión de la información, como soporte fundamental de la transmisión de conocimientos entre, y con, los empleados y otros agentes externos. Ello supone que el trabajo de los empleados del conocimiento se base, además de en las competencias técnicas que poseen, en la utilización de competencias lingüísticas y de comunicación. Gestionar el conocimiento significa gestionar los procesos de creación, desarrollo, difusión y explotación del conocimiento para ganar 
capacidad organizativa y competitiva. Lo que supone, como indican Gallego et alii (2003), optimizar el rendimiento, puesto que se considera el factor humano como la célula del aprendizaje y del desarrollo organizativo. En consecuencia, el capital humano es la pieza esencial, ofreciéndose en el mercado de trabajo mayores oportunidades a aquellos empleados con mayor nivel de cualificación (tanto técnica como lingüística), un trabajo a la vez más autónomo e interrelacionado, basado en el conocimiento, en las ideas y en las iniciativas.

Como destaca Sanchis (1989), ello provoca cambios sustanciales en los perfiles de la mano de obra, entre los que destacan la exigencia de destrezas de interpretación y observación, el carácter predominante del nivel de responsabilidad y autonomía, y la aparición de contenidos no divisibles. La especialización productiva conlleva la polarización del trabajo. Frente a los nuevos productores del capitalismo informacional (Castells, 2000), o empleados del conocimiento "insustituibles", que incluye a un grupo muy grande de ejecutivos, profesionales y técnicos que forman "un trabajador colectivo", existe un amplio grupo de "trabajadores sustituibles", ya sea por máquinas o por otros trabajadores. Los empleados del conocimiento pueden elegir la empresa en la que trabajar, dado que son trabajadores nucleares o esenciales, difíciles de sustituir. Además, obtienen salarios altos, su puesto de trabajo suele ser estable, y tienen capacidad para tomar decisiones sobre su propio trabajo. En cambio, los trabajadores sustituibles se enfrentan a la rotación en el empleo, a salarios bajos, a su sustitución por mano de obra más barata o por sistemas automáticos robotizados. Surge, así, una fractura económica, social, política y cultural, no ya entre empleados de "cuello blanco" y de "cuello azul", sino entre empleados "sustituibles" e "insustituibles".

Además, los empleados del conocimiento deben trabajar frecuentemente con información, la cual está codificada en algún tipo concreto de lenguaje, de manera que en las últimas décadas ha ido aumentando progresivamente la necesidad de utilizar componentes lingüísticos por parte de los empleados "insustituibles", frente a un estancamiento en este sentido de los empleados "sustituibles". El problema a abordar es definir las ocupaciones que se incluyen en cada categoría y cuáles requieren mayores o menores componentes lingüísticos en su trabajo. El presente artículo tiene como objetivo agrupar en una misma categoría aquellas ocupaciones que presentan un nivel de requisitos lingüísticos parecido. Para ello, a partir de la información disponible en la base de datos O'Net para los EE.UU. en el año 2015, se clasifican las ocupaciones laborales (según la clasificación O’NetSOC-2010) en cinco categorías, de mayor a menor requerimiento de competencia lingüística. Dicha clasificación permite realizar análisis comparativos entre ocupaciones, y del impacto que presentan las competencias lingüísticas aplicadas 
en cada ocupación laboral en distintas variables: productividad, empleabilidad, competitividad, etc. La agrupación de las ocupaciones en categorías se efectúa mediante redes neuronales artificiales, a través de mapas autoorganizativos. Ello permite una contribución original y novedosa al campo de estudio, dado que no hay ningún otro trabajo que haya aplicado los SOM para clasificar las ocupaciones laborales en función de sus competencias lingüísticas.

El presente artículo se estructura, a partir de esta introducción, en un segundo apartado que desarrolla el marco conceptual de las competencias lingüísticas en el ámbito de las ocupaciones laborales. A continuación, en el tercer apartado, se expone la metodología y los datos utilizados. En el cuarto apartado se presentan los resultados obtenidos, para pasar, en el quinto, a exponer las conclusiones y debatir los resultados. Se finaliza con la relación de las referencias bibliográficas utilizadas, y los anexos.

\section{Competencias lingüísticas en el ámbito laboral}

El lenguaje se ha convertido en un elemento cada vez más importante en el lugar del trabajo, dado que los "bienes" dejan de ser materiales o tangibles para estar fundamentados progresivamente en componentes lingüísticos de carácter intangible (Chouliaraki y Fairclough, 1999; Flowerdew, 2002). Los tradicionales trabajos industriales han sido reemplazados en gran medida por empleos basados en el conocimiento (van De Mieroop y Clifton, 2018); en organizaciones que eliminan progresivamente la jerarquía para empoderar a los empleados que suelen trabajar en equipos autónomos y autoadministrados. Según Idema y Scheeres (2003), las identidades y valores organizativos se promulgan y transfieren cuando los trabajadores realizan nuevas y diferentes tareas vinculadas con el lenguaje, cuando participan en procesos consultivos y participativos dentro de los equipos de trabajo.

Como señala Isphording (2014), el lenguaje en el lugar de trabajo, y en general, se usa para expresar el estado emocional de la persona, así como para expresar la propia identidad y demandas; es decir, el lenguaje se utiliza como el principal medio de interacción social en el entorno productivo. En este sentido, en las organizaciones, el lenguaje se utiliza para mantener los registros, procesar la información y los hechos ocurridos. Y, más significativamente aún en la Economía del Conocimiento, el lenguaje determina la forma en que los individuos son capaces de pensar y estructurar sus propios pensamientos. En la actualidad, los empleados de cualquier ocupación tienen que interactuar y comunicarse con sus compañeros, con sus superiores jerárquicos, con sus subordinados, e incluso, en algunos casos, con personas externas a la organización (proveedores, distribuido- 
res, clientes...), para transmitir informaciones, ideas, propuestas, resultados, etc. (Fletcher, 2018). Para poder realizar correctamente su trabajo, deben conocer un determinado lenguaje, habitualmente un lenguaje natural, aunque en ocasiones también puede ser de algún otro tipo (matemático, gestual, gráfico, etc.), que facilite la comunicación entre ellos, y la transmisión de informaciones y conocimientos.

La Sociolingüística de la Interacción, iniciada por Gumperz (1982a, 1982b), investiga la diversidad lingüística y cultural como elemento explicativo de las oportunidades económicas, políticas y de otra índole que se les presentan a los individuos. Este concepto se ha utilizado ampliamente en el análisis del lenguaje y de la comunicación en el lugar de trabajo (Gordon y Kraut, 2018). Al respecto, Spencer-Oatey (2008) estableció tres factores que intervienen en una interacción lingüística y comunicativa: a) sensibilidades faciales, b) objetivos de interacción, y c) derechos y obligaciones de la sociabilidad. La sensibilidad facial hace referencia al valor social positivo que reclama una persona en los otros cuando interactúa con ellos. Los objetivos de la interacción se refieren a las influencias del tipo de actividad que se ejerce y los roles que se adoptan en las relaciones sociales entre los participantes en una interacción comunicativa. El tercer factor, los derechos y obligaciones de la sociabilidad, consiste en hacer explícitos los derechos sociales fundamentales que cada persona reclama, y que están en función de las normas sociales y de los comportamientos socialmente aceptados en cada cultura. En el lugar de trabajo, por ejemplo, pueden hacer referencia a las convenciones que regulan lo que se considera un comportamiento adecuado, en función del rol desempeñado, en una reunión, en una conversación con un cliente, en una entrevista de trabajo, en la negociación de un contrato, etc. Estos tres factores, sin duda, implican que los empleados dispongan de habilidades lingüísticas y comunicativas adecuadas a las funciones que deben desarrollar en su puesto de trabajo.

Para Isphording (2014), las habilidades lingüísticas que requieren los empleados han ido aumentando durante las últimas décadas, en un proceso que se presupone que continuará creciendo en los próximos años. La transformación del mercado de trabajo hacia una producción cada vez más basada en la información y el conocimiento ha aumentado drásticamente la necesidad de habilidades lingüísticas por parte de los empleados. Con la aparición y difusión del uso de las TIC, prácticamente no hay ocupaciones que no requieran un mínimo de habilidades para hablar, escribir y leer. Como afirma Heller (2005), en la Economía del Conocimiento las nuevas condiciones económicas hacen que los empleados ya no vendan su esfuerzo físico, sino su trabajo intelectual y comunicativo. No obstante, hay ocupaciones que requieren un mayor dominio de habilidades lingüísticas y 
de comunicación que otras. Según Alarcón et al. (2014), las ocupaciones que para desempeñarlas necesitan una certificación educativa (como por ejemplo abogados y médicos) requieren un conjunto de habilidades lingüísticas avanzadas; incluso los puestos de gerencia media a alta generalmente también requieren de un dominio elevado de habilidades lingüísticas. Los trabajadores que acceden a estas ocupaciones precisan del correspondiente certificado académico, el cual presupone un determinado nivel de competencia lingüística. Como indican Chiswick y Miller (2010), las personas se autoseleccionan en ocupaciones que se ajustan mejor a sus habilidades lingüísticas.

Tabla 1. Tipología de ocupaciones en función de su perfil lingüístico.

\begin{tabular}{|c|c|c|c|c|}
\hline Perfil & Descripción & Caracteristicas Lingüisticas & Subgrupos & Ejemplos de ocupaciones \\
\hline \multirow{4}{*}{ Perfil A } & \multirow{4}{*}{$\begin{array}{l}\text { Analistas } \\
\text { simbólicos de } \\
\text { perfil alto }\end{array}$} & \multirow{4}{*}{ 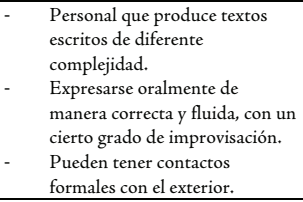 } & A1. Alta Dirección & $\begin{array}{l}\text { Director ejecutivo, Director de } \\
\text { recursos humanos, etc. }\end{array}$ \\
\hline & & & A2. Profesionales & Juristas, Economistas, etc. \\
\hline & & & A3. Baja Gerencia & Supervisores de primera línea, \\
\hline & & & $\begin{array}{l}\text { A4. Analistas simbólicos de } \\
\text { perfil alto, pero no directivos }\end{array}$ & $\begin{array}{l}\text { Especialistas en relaciones } \\
\text { públicas, Especialistas en } \\
\text { sistemas informáticos, etc. }\end{array}$ \\
\hline \multirow[t]{2}{*}{ Perfil B } & \multirow{2}{*}{$\begin{array}{l}\text { Analistas } \\
\text { simbólicos de } \\
\text { perfil bajo }\end{array}$} & \multirow{2}{*}{$\begin{array}{l}\text { - Personal que produce textos } \\
\text { escritos cortos o emparejados. } \\
\text { - Producir mensajes orales de } \\
\text { poca complejidad. } \\
\text { Pueden tener contactos orales } \\
\text { con el público. }\end{array}$} & $\begin{array}{l}\text { B1. Analistas simbólicos de } \\
\text { perfil bajo con escasa } \\
\text { probabilidad de interacción } \\
\text { con el público }\end{array}$ & $\begin{array}{l}\text { Personal administrativo, } \\
\text { Secretarios de archivo, etc. }\end{array}$ \\
\hline & & & $\begin{array}{l}\text { B2. Analistas simbólicos de } \\
\text { perfil bajo con elevada } \\
\text { probabilidad de interacción } \\
\text { con el público }\end{array}$ & $\begin{array}{l}\text { Asistentes personales, } \\
\text { secretariado, etc. }\end{array}$ \\
\hline \multirow{4}{*}{ Perfil C } & \multirow{4}{*}{$\begin{array}{l}\text { Trabajadores de } \\
\text { atención a } \\
\text { personas de } \\
\text { perfil alto }\end{array}$} & \multirow{4}{*}{$\begin{array}{l}\text { El personal que debe } \\
\text { proporcionar información oral } \\
\text { básica en su lugar de trabajo, la } \\
\text { cual se considera importante } \\
\text { para la imagen de la } \\
\text { organización. } \\
\text { Producir mensajes orales y } \\
\text { fluidos. }\end{array}$} & C1. Enfermeras & Enfermeras \\
\hline & & & $\begin{array}{l}\text { C2. Asistentes y técnicos de } \\
\text { servicios públicos }\end{array}$ & $\begin{array}{l}\text { Técnicos médicos, Vendedores, } \\
\text { Telefonistas, etc. }\end{array}$ \\
\hline & & & C3. Policía, etc. & $\begin{array}{l}\text { Policía, Detectives, } \\
\text { Investigadores privados, etc. }\end{array}$ \\
\hline & & & $\begin{array}{l}\text { C4. Bomberos, técnicos de } \\
\text { emergencias médicas }\end{array}$ & $\begin{array}{l}\text { Bomberos, Técnicos de } \\
\text { emergencias médicas }\end{array}$ \\
\hline Perfil D & $\begin{array}{l}\text { Trabajadores de } \\
\text { atención a } \\
\text { personas de } \\
\text { perfil bajo }\end{array}$ & $\begin{array}{l}\text { Personal que tiene contacto con } \\
\text { el público para información de } \\
\text { primeros auxilios. } \\
\text { - Producir mensajes orales cortos } \\
\text { y sencillos. } \\
\text { - No produce textos escritos. }\end{array}$ & $\begin{array}{l}\text { D1. Miscelánea (sin } \\
\text { subcategorías) }\end{array}$ & $\begin{array}{l}\text { Porteros, mayordomos, } \\
\text { Conserjes, Recepcionistas, } \\
\text { Guardias de seguridad, etc. }\end{array}$ \\
\hline \multirow[t]{2}{*}{ Perfil E } & \multirow{2}{*}{$\begin{array}{l}\text { Trabajadores de } \\
\text { producción y } \\
\text { empleos } \\
\text { rutinarios }\end{array}$} & \multirow{2}{*}{$\begin{array}{l}\text { - Personal que no tiene contacto } \\
\text { con el exterior, ni oral ni escrito. } \\
\text { Comprender comunicaciones } \\
\text { muy básicas de la organización o } \\
\text { del exterior, relacionadas con su } \\
\text { trabajo específico. }\end{array}$} & $\begin{array}{l}\text { E1. Trabajadores manuales } \\
\text { cualificados }\end{array}$ & $\begin{array}{l}\text { Operadores de producción, } \\
\text { Fontaneros, Electricistas, etc. }\end{array}$ \\
\hline & & & $\begin{array}{l}\text { E2. Trabajadores manuales } \\
\text { no cualificados }\end{array}$ & Personal de almacén, Peones, etc. \\
\hline
\end{tabular}

Fuente: Adaptado de Alarcón et alii (2014).

Las ocupaciones pueden agruparse en distintas categorías en función del uso que requieran de habilidades lingüísticas. Alarcón et al. (2014) construyen una clasificación de acuerdo al papel que ejerce el lenguaje en el lugar de trabajo, la cual, a pesar de ser de carácter cualitativo e intuitivo, es consistente con el concepto de intensidad lingüística en los procesos de producción (Reich, 1991; Grin et alii, 2010). La clasificación de las ocupaciones en función de sus perfiles 
lingüísticos realizada por Alarcón et alii (2014), reflejada en la Tabla 1, es un excelente instrumento conceptual, que pone de manifiesto la existencia de distintas exigencias de competencia lingüística en las diferentes ocupaciones. Además, permite distinguir de forma gradual entre ocupaciones con alto contenido simbólico y lingüístico (que dan trabajo a empleados "insustituibles") de aquellas otras ocupaciones con un bajo contenido simbólico y lingüístico (que dan trabajo a empleados "sustituibles").

Sin embargo, su traslación al ámbito empírico puede generar problemas, ya que cada investigador/a tendría que clasificar las distintas ocupaciones en uno de los cinco grupos o perfiles en función de sus apreciaciones subjetivas. Ello podría suponer que distintos investigadores clasificaran una misma ocupación en grupos diferentes, dando lugar a dificultades de comparación entre los resultados de distintas investigaciones. La aplicación de redes neuronales artificiales, y en concreto de los mapas autoorganizativos de Kohonen, permite obtener una clasificación de las ocupaciones de forma objetiva, a través de un algoritmo matemático y que, por tanto, favorece la homogeneidad de los grupos obtenidos y permite un mayor o menor nivel de agrupación en función de los intereses del investigador/a.

\section{Metodología y datos}

\subsection{Los mapas autoorganizativos de Kohonen}

Con la finalidad de agrupar las ocupaciones en diferentes categorías en función del nivel de requerimiento de sus competencias lingüísticas, se ha utilizado un tipo particular de red neuronal artificial (RNA), en concreto se han aplicado los mapas autoorganizativos de Kohonen (SOM, por su terminología en inglés: SelfOrganizing Maps).

Las RNA tienen su origen en el matemático Alan M. Turing (1937) quien estudió el cerebro humano como una forma de entender la computación. Posteriormente, en 1943, Warren McCulloch y Walter Pitts (neurofisiólogo y matemático, respectivamente) desarrollaron las bases teóricas de la computación neuronal. Diversos científicos siguieron sus pasos, dando lugar a diferentes tipos de RNA, siendo la más antigua de ellas el perceptrón de una sola capa desarrollada por Rosenblatt (1958). Actualmente, existe una gran variedad de RNA (Arbib, 2003) con múltiples aplicaciones en el campo económico, médico, industrial y en el de la adquisición y procesamiento del lenguaje, entre otros. Además, se está potenciando su uso mediante la combinación de RNA con otras metodologías propias de la inteligencia artificial. 
De las diferentes definiciones de RNA, destaca la de Kohonen (1988:4), según la cual "las redes neuronales artificiales son redes interconectadas masivamente en paralelo de elementos simples (usualmente adaptativos) y con organización jerárquica, las cuales intentan interactuar con los objetos del mundo real del mismo modo que lo hace el sistema nervioso biológico." Así, una RNA es un programa informático (aunque no todo programa informático es una RNA) cuyo funcionamiento requiere de una inspiración biológica. Se caracteriza por estar formada por unidades de procesamiento simples (las neuronas o unidades de la red) pero altamente conexionadas entre sí (al igual que las sinapsis de nuestras neuronas). El aprendizaje en la red es de naturaleza inductiva y se lleva a cabo mediante la modificación de los pesos asociados a las conexiones entre neuronas.

Dentro de las RNA se pueden distinguir dos clases: las RNA supervisadas, que requieren de un agente externo que conoce la salida del sistema y proporciona información a la red para que modifique los pesos durante la etapa de entrenamiento; y las redes no supervisadas, que utilizan propiedades internas de los datos de entrada para, usualmente, encontrar una relación entre ellos. Los SOM forman parte de este segundo tipo de RNA.

Los SOM fueron desarrollados por Teuvo Kohonen en 1982. Este tipo de RNA se basa en la propiedad que tiene nuestro cerebro de almacenar los recuerdos de una forma organizada, en lugar de hacerlo de forma aleatoria. Es decir, los recuerdos se estructuran de manera que aquellos que son parecidos quedan almacenados en zonas próximas del cerebro, mientras que los recuerdos con menos similitudes quedan almacenados en zonas más alejadas. Recogiendo esta característica, Kohonen (1988) diseñó una RNA que organiza la información de entrada ( $n$-dimensional) en mapas inicialmente unidimensionales, que posteriormente pasaron a ser bidimensionales (hoy en día también es posible obtener mapas de tres dimensiones).

El objetivo de una SOM es ubicar en un mapa (en nuestro caso, bidimensional) un conjunto de patrones (ocupaciones) que están definidos por un número elevado de componentes (variables relacionadas con los requerimientos de competencias lingüísticas de las diversas ocupaciones) que dificultan su agrupación si se tienen en cuenta conjuntamente todas las características que los definen. Para ello, la SOM se compone de dos capas de neuronas. La capa de entrada, con tantas neuronas como componentes se utilicen para definir el patrón, recoge la información de entrada y la transfiere a la capa de salida. Esta segunda capa, en forma de mapa rectangular o hexagonal, muestra la ubicación de cada patrón (ocupación) teniendo en cuenta que cuánto más cerca se hallen dos patrones (ocupaciones) en el mapa, más similitud existirá entre las características de ambos. Su posición 
en el mapa, además, vendrá determinada por el valor que tome cada una de esas características (variables de competencias lingüísticas) en la zona del mapa que está ocupando. Se dice que los SOM son autoorganizativos ya que la ubicación de los patrones en el mapa se determina por la semejanza existente entre dichos patrones, sin la intervención de ningún agente externo y sin la necesidad de definir, previamente, las clases en las que se agruparán los patrones.

De forma resumida, un SOM funciona de la siguiente manera. En primer lugar, se construyen los vectores con los valores de las componentes que caracterizan a cada patrón. A continuación, se propaga esta información a las unidades de la capa de salida, viéndose afectados los valores de las componentes por el peso asociado a la conexión de las neuronas de entrada a las de salida (estos pesos inicialmente son aleatorios y se modifican a medida que la red aprende). Se determina la neurona ganadora, siendo aquella unidad del mapa de salida que presenta mayor similitud con la información de entrada (normalmente, se utiliza como métrica la distancia euclidea). Finalmente, se modifican los pesos de las conexiones de la neurona ganadora y sus vecinas (neuronas cercanas a la ganadora delimitadas por un radio de vecindad que va disminuyendo con el número de iteraciones). A continuación, se repite este mismo proceso con el resto de patrones. Una vez los patrones se han estabilizad o en una zona del mapa, pueden establecerse grupos utilizando algún método de agrupación como puede ser el algoritmo $k$-means. Para la implementación de los SOM se ha utilizado la Toolbox para Matlab desarrollada por el Laboratory of Computer and Information Science de la Helsinki University of Technology.

\subsection{Datos y variables}

Los datos se han obtenido de la base de datos O'Net para EE.UU. en 2015, que sigue la taxonomía, aunque ampliada, de la SOC-2010. La base de datos O'Net contiene un amplio conjunto de variables que describen las características del trabajo y del trabajador, incluyendo el nivel requerido de competencias y habilidades en cada ocupación, entre otras, en relación a competencias lingüísticas. La base de datos O’Net-SOC-2010 se estructura en 4 niveles de agregación, de más genéricas a más específicas: a) Grupos Principales (Major Groups), que agrupa las ocupaciones en 23 grandes grupos; b) Grupos Menores (Minor Groups), en 96; c) Ocupaciones Amplias (Broad Occupations), en 449, y d) Ocupaciones Detalladas (Detailed Occupations), en 821 ocupaciones específicas.

La base de datos O'Net, gestionada por the US Department of Labor, se actualiza continuamente mediante una encuesta a una amplia gama de expertos $y$ trabajadores de cada ocupación. La información de esta base de datos de libre ac- 
ceso constituye el núcleo de O’Net OnLine (<https://www.onetonline.org/>), una aplicación interactiva para explorar las ocupaciones. Las características clave de cada ocupación se describen mediante un conjunto medible y estandarizado de variables, que describen una gran multiplicidad de habilidades y competencias laborales. En la recopilación de la información mediante encuesta, se pregunta sobre el nivel requerido en relación a una habilidad o competencia concreta para desempeñar correctamente el trabajo en esa ocupación, siguiendo las preguntas el esquema: "What level of the skill / ability / knowledge [...] is needed to perform your current job?” (¿Qué nivel de habilidad / capacidad / conocimiento en [...] se necesita para realizar su trabajo actual?). Para medir el nivel requerido de cada competencia se utiliza una escala de Likert de siete puntos, donde el 7 representa el Nivel más Alto y el 1 el Nivel más Bajo requerido. Los encuestados que consideran que alguna de las habilidades o competencias sobre las que se les pregunta no son en absoluto importantes (es decir, que no se aplican) para el desempeño de su trabajo, O’Net las codifica con un cero (0), motivo por el cual la escala resultante es de ocho puntos $(0-7)$. Con la finalidad de facilitar la interpretación, el valor promedio obtenido para cada pregunta y ocupación se estandariza en una escala de 0 a 100 puntos.

Tabla 2. Variables iniciales para medir las competencias lingüísticas ( $\left.\mathrm{O}^{\prime} \mathrm{Net}\right)$.

\begin{tabular}{|l|l|l|}
\hline Código & Competencia Lingüística & Descripción \\
\hline Var1 & Comprensión oral & $\begin{array}{l}\text { La capacidad de escuchar y comprender la información y las ideas } \\
\text { presentadas a través de palabras y oraciones. }\end{array}$ \\
\hline Var2 & Expresión oral & $\begin{array}{l}\text { La capacidad de comunicar información e ideas al hablar de forma } \\
\text { comprensible. }\end{array}$ \\
\hline Var3 & Comprensión escrita & $\begin{array}{l}\text { La capacidad de leer y comprender información e ideas presentadas por } \\
\text { escrito. }\end{array}$ \\
\hline Var4 & Expresión escrita & $\begin{array}{l}\text { La capacidad de comunicar información e ideas por escrito de forma } \\
\text { comprensible. }\end{array}$ \\
\hline Var5 & Claridad en el discurso & La habilidad de hablar claramente. \\
\hline Var6 & Reconocimiento del habla & La capacidad de identificar y entender el habla de otra persona. \\
\hline Var7 & Conocimiento del inglés & $\begin{array}{l}\text { Conocimiento de la estructura y el contenido del idioma inglés, incluido el } \\
\text { significado y la ortografía de las palabras, las reglas de composición y la } \\
\text { gramática. }\end{array}$ \\
\hline Var8 & Comprensión lectora & $\begin{array}{l}\text { Comprensión de frases y párrafos escritos en documentos relacionados con } \\
\text { el trabajo. }\end{array}$ \\
\hline Var9 & Habilidad de hablar & Capacidad de transmitir información oral de manera efectiva. \\
\hline Var10 & Habilidad de escribir & $\begin{array}{l}\text { Comunicarse de manera efectiva por escrito según corresponda a las } \\
\text { necesidades de la audiencia. }\end{array}$ \\
\hline Var11 & $\begin{array}{l}\text { Comunicación con personas ajenas } \\
\text { a la organización }\end{array}$ & $\begin{array}{l}\text { Comunicarse con personas externas a la organización, representando a la } \\
\text { organización ante los clientes, el público, el gobierno y otras fuentes } \\
\text { externasta Esta información se puede intercambiar en persona, por escrito, } \\
\text { por telono o correo electrónico. }\end{array}$ \\
\hline Var12 & $\begin{array}{l}\text { Comunicación con superiores, } \\
\text { iguales o subordinados }\end{array}$ & $\begin{array}{l}\text { Proporcionar información a los supervisores, compañeros/as de trabajo y } \\
\text { subordinados/as por teléfono, por escrito, correo electrónico o en persona. }\end{array}$ \\
\hline
\end{tabular}

Fuente: Elaboración propia, a partir de O’Net OnLine (https://www.onetonline.org/). 
De entre todas las competencias laborales sobre las que ofrece información O’Net, únicamente se han considerado 12 variables, aquellas que más directamente suponen la utilización de competencias lingüísticas en el trabajo. Dichas variables quedan recogidas y descritas en la Tabla 2.

Una vez analizada la matriz de coeficientes de correlación se han detectado variables altamente correlacionadas. Para evitar que la SOM sobrepondere dichas variables, se ha procedido a reducir el número de variables, considerando las 8 recogidas en la Tabla 3. Concretamente la media de las variables 1 y 2 se utiliza para medir las habilidades orales de las ocupaciones laborales; $y$ la media de las variables 3,4 y 10 para medir las habilidades escritas. Finalmente, no se considera la variable 8 (comprensión lectora), por estar altamente correlacionada con la variable 4 (expresión escrita).

Tabla 3. Variables utilizadas para definir las ocupaciones laborales a partir de sus competencias lingüísticas.

\begin{tabular}{|l|l|l|}
\hline $\mathrm{X}_{1}$ & Media (Var1, Var2) & Habilidades orales \\
\hline $\mathrm{X}_{2}$ & Media (Var3,Var4,Var10) & Habilidades escritas \\
\hline $\mathrm{X}_{3}$ & Var5 & Claridad en el discurso \\
\hline $\mathrm{X}_{4}$ & Var6 & Reconocimiento del habla \\
\hline $\mathrm{X}_{5}$ & Var7 & Conocimiento del inglés \\
\hline $\mathrm{X}_{6}$ & Var9 & Habilidad de hablar \\
\hline $\mathrm{X}_{7}$ & Var11 & Comunicación con personas ajenas a la organización \\
\hline $\mathrm{X}_{8}$ & Var12 & Comunicación con superiores, iguales o subordinados \\
\hline
\end{tabular}

De esta forma, cada ocupación $\mathrm{P}$ queda definida a partir de un vector de 8 componentes $\mathrm{X}^{\mathrm{P}}=\left(\mathrm{X}_{1}{ }^{\mathrm{P}}, \mathrm{X}_{2}{ }^{\mathrm{P}}, \ldots, \mathrm{X}_{8}{ }^{\mathrm{P}}\right)$, donde $\mathrm{X}_{1}^{\mathrm{P}}$ recoge el nivel requerido en habilidades orales para la profesión $\mathrm{P}, \mathrm{X}_{2}{ }^{\mathrm{P}}$ recoge el nivel requerido en habilidades escritas para la profesión $\mathrm{P}$, etc.

\section{Resultados}

El análisis se realiza para los 3 niveles de agregación más específicos, descartando el Grupo Principal (Major Group) por el reducido número de grupos que incluye. No se han considerado aquellas ocupaciones o agrupaciones para las cuales no se disponía de datos para las 8 variables, considerándose un total de 94 grupos en la categoría de Grupos Menores (Minor Groups), 435 en la de Ocupaciones Amplias (Broad Occupations) y 754 en la de Ocupaciones Detalladas (Detailed Occupations). 
El SOM resultante para la categoría Grupos Menores (Minor Groups) se muestra en el Anexo 1. La interpretación del lugar que ocupa cada profesión en el mapa requiere de los mapas de características que se ofrecen en el Anexo 2. Las ocupaciones que se sitúan en la parte superior del SOM son las que tienen unos valores más bajos en todas las competencias lingüísticas (ocupan la zona azul en los mapas del Anexo 2), mientras que las profesiones situadas en la parte inferior del mapa se corresponden con las ocupaciones que requieren de mayores competencias lingüísticas.

Se ha realizado el mismo análisis para los niveles Ocupaciones Amplias (Broad) y Ocupaciones Detalladas (Detailed). Posteriormente, utilizando el algoritmo k-means, se han agrupado las ocupaciones teniendo en cuenta que haya la máxima homogeneidad entre las ocupaciones que forman un grupo. Para facilitar la comparación se han establecido cinco grupos en cada uno de los tres niveles de agrupación (Grupos Menores, Ocupaciones Amplias y Ocupaciones Detalladas). Además permite su comparación con la clasificación de Alarcón et al. (2014), que también consta de cinco perfiles de ocupaciones en función de su intensidad lingüística. A continuación, se han relacionado las ocupaciones que pertenecen a cada familia de profesiones según los niveles de O'Net y se han coloreado en función del grupo al que pertenecen en el SOM de cada nivel, en una escala de color: el rojo corresponde a los grupos con mayores requerimientos de competencias lingüísticas, el naranja al segundo grupo con mayores competencias, el amarillo al grupo con un requerimiento medio, el verde a un nivel bajo de competencias $y$ el azul al grupo con menor exigencia en cuanto a competencias lingüísticas. En la Tabla 4 se presenta una clasificación simplificada de los cinco grupos obtenidos, al nivel de agregación Ocupaciones Detalladas (la relación completa para el conjunto de las 754 ocupaciones analizadas puede verse en el Anexo 3). 
Tabla 4. Ejemplo de clasificación de las ocupaciones (al nivel Ocupaciones Detalladas) en cinco grupos o perfiles lingüísticos, obtenida a partir de la aplicación de la SOM.

\begin{tabular}{|c|c|c|}
\hline Perfil / Grupo & Descripción & $\begin{array}{l}\text { Ejemplos de ocupaciones } \\
\text { (código O'Net-SOC-2010) }\end{array}$ \\
\hline Perfil / Grupo A & $\begin{array}{l}\text { Ocupaciones que presentan un } \\
\text { nivel muy alto de demanda en } \\
\text { términos de competencias } \\
\text { lingüísticas }\end{array}$ & 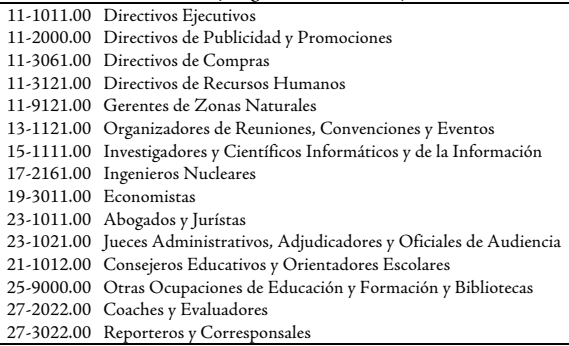 \\
\hline Perfil / Grupo B & $\begin{array}{l}\text { Ocupaciones que presentan un } \\
\text { nivel alto de demanda en } \\
\text { términos de competencias } \\
\text { lingüísticas, pero inferior grupo } \\
\text { anterior }\end{array}$ & 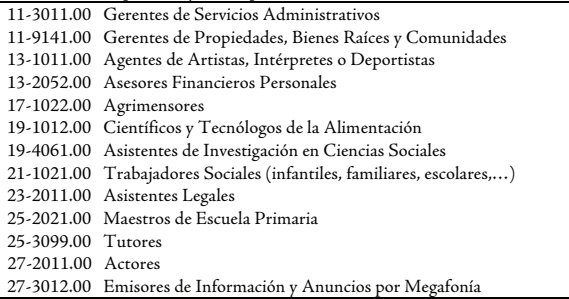 \\
\hline Perfil / Grupo C & $\begin{array}{l}\text { Ocupaciones que presentan un } \\
\text { nivel intermedio en términos de } \\
\text { competencias lingüísticas }\end{array}$ & $\begin{array}{ll}\text { 11-9031.00 } & \text { Administradores de Centros Escolares (guardería, preescolar) } \\
\text { 13-1032.00 } & \text { Tasadores de Seguros } \\
\text { 15-1131.00 } & \text { Programadores Informáticos } \\
\text { 17-3024.00 } & \text { Técnicos Electro-Mecánicos } \\
\text { 27-1022.00 } & \text { Diseñadores de Moda } \\
\text { 27-2032.00 } & \text { Coreógrafos } \\
\text { 27-4031.00 } & \text { Operadores de Cámara (televisión, video, películas,...) } \\
\text { 29-2056.00 } & \text { Tecnólogos y Técnicos Veterinarios } \\
\text { 31-9092.00 } & \text { Asistentes Médicos } \\
\text { 33-3052.00 } & \text { Policía de Tráfico } \\
\text { 39-1021.00 } & \text { Supervisores de Línea y Trabajadores de Servicios Personales } \\
\text { 43-4081.00 } & \text { Recepcionistas (hotel, motel, centro turístico,...) } \\
\text { 43-5061.00 } & \text { Empleados Cualificados de Producción } \\
\text { 53-2031.00 } & \text { Auxiliares de Vuelo }\end{array}$ \\
\hline Perfil / Grupo D & $\begin{array}{l}\text { Ocupaciones que presentan un } \\
\text { nivel bajo de demanda en } \\
\text { términos de competencias } \\
\text { lingǘsticas, pero superior al } \\
\text { grupo siguiente }\end{array}$ & 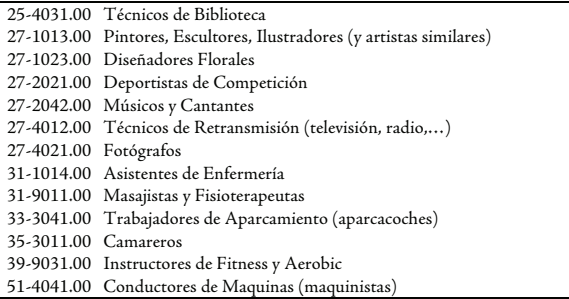 \\
\hline Perfil / Grupo E & $\begin{array}{l}\text { Ocupaciones que presentan un } \\
\text { nivel muy bajo de demanda en } \\
\text { términos de competencias } \\
\text { lingüísticas }\end{array}$ & $\begin{array}{ll}\text { 27-1012.00 } & \text { Artistas Artesanos } \\
\text { 31-1015.00 } & \text { Ordenanzas } \\
\text { 33-9091.00 } & \text { Guardias de Cruce (Ayuda a Peatones en Intersecciones) } \\
\text { 35-2021.00 } & \text { Manipuladores de Alimentos } \\
\text { 37-2011.00 } & \text { Porteros y Limpiadores } \\
\text { 39-3021.00 } & \text { Proyeccionistas de Películas } \\
\text { 39-5011.00 } & \text { Barberos y Peluqueros } \\
\text { 39-6011.00 } & \text { Botones y Porteadores de Equipajes } \\
\text { 41-9012.00 } & \text { Modelos } \\
\text { 43-5052.00 } & \text { Transportistas de Correos } \\
\text { 45-3021.00 } & \text { Cazadores y Tramperos } \\
\text { 47-2061.00 } & \text { Trabajadores no Cualificados de la Construcción } \\
\text { 47-5041.00 } & \text { Operadores de Maquinaria de Minería } \\
\text { 49-9011.00 } & \text { Reparadores Mecánicos de Puertas } \\
\text { 53-7011.00 } & \text { Transportistas (camioneros) y Reponedores en Tiendas }\end{array}$ \\
\hline
\end{tabular}


A nivel conceptual, existe una correspondencia entre la clasificación obtenida a partir de la aplicación de la SOM y la establecida por Alarcón et alii (2014). Ello sugiere que la SOM proporciona una correcta clasificación de las ocupaciones en función de sus exigencias de competencias lingüísticas, a la vez que solventa los posibles problemas de clasificación intuitiva y subjetiva de las ocupaciones que presenta la tipología de Alarcón et al. (2014).

Por otro lado, de los resultados obtenidos se desprende que existen algunos niveles de ocupaciones con una clara homogeneidad en cuanto a competencias lingüísticas dentro de todas las ocupaciones que forman el nivel agregado. Por ejemplo, el Grupo Menor (Minor) con código 11.2000 (Directivos de Publicidad y Promociones) pertenece al grupo con mayor requerimiento de competencias lingüísticas (Perfil A, véase Tabla 4). Dentro de dicho grupo, a nivel de Ocupaciones Amplias (Broad) se incluyen los códigos 11-2010, 11-2020 y 11-2030 (Gerentes de Publicidad y Promociones; Gerentes de Marketing y Ventas; y Gerentes de Relaciones Públicas y Recaudadores de Fondos, respectivamente) que también pertenecen al grupo con mayor nivel de exigencia. $Y$ a nivel de Ocupaciones Detalladas (Detailed), se encuentran los códigos 11-2011.00, 11-2021.00, 11-2022.00 y 11-2031.00 (Gerentes de Publicidad y Promociones, Gerentes de Marketing, Gerentes de Ventas, y Gerentes de Relaciones Públicas y Recaudadores de Fondos, respectivamente) que también se han clasificado en el primer grupo en cuanto a competencias lingüísticas (Perfil A, véase Anexo 3).

No obstante, se encuentran otros niveles de ocupaciones en los que no se da esta correspondencia, encontrándose diferencias substanciales entre los requerimientos lingüísticos en función del nivel de agregación considerado. Si se analiza la categoría del Grupo Menor (Minor) con código 25.9000 (Otras Ocupaciones de Educación y Formación y Bibliotecas), este nivel se clasifica dentro del grupo con mayores requerimientos lingüísticos (Perfil A, véase Tabla 4). En su desagregación, a nivel de Ocupaciones Amplias (Broad), se distinguen dos ocupaciones que también se ubican en el grupo con mayor exigencia lingüística o Perfil A (25.9020: Asesores de Gestores de Granjas Escuela, y 25.9030: Coordinadores de Instrucción), pero en cambio se encuentra una ocupación en el Perfil B (25.9010: Especialistas en Audiovisual y Multimedia) e incluso una ocupación que queda ubicada dentro de un grupo con un nivel bajo de competencias, en el Perfil D (25.9040: Asistentes de Maestros) (véase Anexo 3).

Estas discrepancias de clasificación en función del nivel de desagregación de las ocupaciones que se considere se debe a que O'Net ordena y codifica las ocupaciones por familias o ramas de actividad laboral, es decir agrupa las ocupaciones a partir de su afinidad laboral, sin tener en cuenta el status profesional o catego- 
ría laboral que tiene cada una de ellas. En consecuencia, cuando se clasifican las ocupaciones por los requerimientos de competencia lingüística surgen, en ocasiones, las disparidades comentadas en función del nivel de desagregación. Así, dentro de un mismo Grupo Menor (Minor) pueden incorporarse ocupaciones a nivel de Ocupaciones Amplias (Broad) y de Ocupaciones Detalladas (Detailed) que presenten distintos niveles requeridos de competencia lingüística en función de su status profesional y categoría laboral. Por tanto, resulta extremadamente importante tener en cuenta este hecho, dado que, de otro modo, se cometerían errores al asumir que dentro de determinados Grupos Menores (Minor) existe una sustitución entre ocupaciones con requerimientos similares, ya que en un nivel de Ocupaciones Detalladas (Detailed) muestran diferencias substanciales. Un ejemplo claro de ello se detalla en la Tabla 5.

Tabla 5. Clasificación de las ocupaciones con código 41.9000 (Otros Trabajadores de Ventas y Relacionados), en función del requerimiento de competencias lingüísticas.

\begin{tabular}{|c|r|r|l|}
\hline $\begin{array}{c}\text { Grupo } \\
\text { Menor } \\
\text { (Minor) }\end{array}$ & $\begin{array}{c}\text { Ocupaciones } \\
\text { Amplias } \\
\text { (Broad) }\end{array}$ & $\begin{array}{c}\text { Ocupaciones } \\
\text { Detalladas } \\
\text { (Detailed) }\end{array}$ & Ocupación \\
\hline \multirow{4}{*}{$41-9000$} & $41-9010$ & $41-9011.00$ & Demostradores y Promotores de Productos \\
\cline { 2 - 5 } & $41-9012.00$ & Modelos \\
\cline { 2 - 5 } & $41-9020$ & $41-9021.00$ & Corredores de Bienes Raíces \\
\cline { 2 - 5 } & $41-9030$ & $41-9022.00$ & Agentes de Ventas de Bienes Raíces \\
\cline { 2 - 5 } & $41-9041.00$ & Ingenieros de Ventas \\
\cline { 2 - 5 } & $41-9090$ & $41-9041.00$ & Televendedores \\
\hline
\end{tabular}

Al nivel de agregación de Ocupaciones Detalladas (Detailed), se observa que la ocupación con código 41-9011.00 (demostradores y promotores de productos) se clasifica en cuanto al requerimiento de competencias lingüísticas (ver Tabla 4) en el Perfil C, la ocupación 41-9012.00 (modelos) en el Perfil E, las ocupaciones 41-9021.00 (corredores de bienes raíces) y 41-9022.00 (agentes de ventas de bines raíces) pertenecen al Perfil B, la ocupación 41-9031.00 (ingenieros de ventas) al Perfil A, la ocupación 41-9041.00 (televendedores) al Perfil D, y la ocupación 41-9091.00 (vendedores puerta a puerta, vendedores ambulantes) al Perfil C. Al nivel de Ocupaciones Amplias (Broad), el resultado es ligeramente diferente; así las ocupaciones englobadas en el código 41-9020 se encuadran conjuntamente en el Perfil E, las del código 41-9020 en el Perfil B, las del código 41-9030 en el Perfil A, y las del código 41-9040 y 41-9090 en el Perfil C. Finalmente, al nivel de agregación de las ocupaciones de Grupo Menor (Minor) la clasificación obtenida 
en conjunto para todas las ocupaciones del código 41-9000 (otros trabajadores de ventas y relacionados) es el Perfil C, ya que se considera para definir los requerimientos lingüísticos de este Grupo Menor (Minor) los valores medios de todas las ocupaciones incluidas en él.

En consecuencia, aunque en algunas ocupaciones los requerimientos lingüísticos del nivel Grupo Menor (Minor) pueden generalizarse a todas las ocupaciones incluidas en los demás niveles, debe tenerse en cuenta que existen otras ocupaciones en las que es importante descender a un nivel más específico (Ocupaciones Amplias o Detalladas) para conocer las necesidades lingüísticas reales de una ocupación concreta. Es decir, se recomienda trabajar siempre con la clasificación a nivel de Ocupaciones detalladas (Detailed). Y ello, debido a que la agregación en niveles de las ocupaciones en la base de datos O'Net-SOC se lleva a cabo por similitud de tareas y ramas de actividad, y no por sus requerimientos de competencias lingüísticas.

\section{Debate y conclusiones}

Utilizando los mapas autoorganizativos de Kohonen (SOM) se han agrupado 754 ocupaciones de la base de datos O'Net-SOC-2010 en cinco grupos que suponen una gradación de las ocupaciones en función de los requerimientos lingüísticos (a partir de 8 variables que recogen competencias relacionadas con la expresión oral y escrita) que deben poseer los empleados que las desempeñan.

La clasificación a partir de datos empíricos tiene la ventaja sobre otras tipologías conceptuales de carácter intuitivo y subjetivo existentes; al haber sido obtenida utilizando una metodología que puede ser replicada por otros investigadores/ as. Además, los cinco grupos o perfiles de ocupaciones que se han generado son coherentes con las clasificaciones conceptuales, en especial con la de Alarcón et alii (2014), lo cual sugiere que la metodología utilizada es útil para el objetivo propuesto en el artículo.

A nivel conceptual, tal como se pone de manifiesto en la Tabla 4, el grupo o perfil A se corresponde con aquellas ocupaciones que requieren de un mayor nivel de competencias lingüísticas (mayor capacidad para hablar con discursos claros, una elevada capacidad de escritura y lectura, de comunicación con otras personas y de escucha), se trata de ocupaciones en la que se exige para su correcto desempeño de niveles lingüísticos y simbólicos considerablemente altos. El grupo B engloba las ocupaciones que presentan parecidas características de competencias lingüísticas que el grupo anterior, es decir a un nivel alto, pero no tan elevado como en el grupo A; se trata de ocupaciones que requieren que los empleados que las desempeñan hablen, escriban, lean, escuchen y se comuniquen 
con otras personas, pero no se les exige niveles lingüísticos y simbólicos tan elevados. El grupo $\mathrm{C}$ presenta un nivel medio de competencias lingüísticas, se trata de ocupaciones que requieren que los empleados hablen, escriban, lean y escuchen, pero con menor intensidad que en los grupos anteriores, ya que dichas competencias lingüísticas únicamente las necesitan en determinadas situaciones y con relativa frecuencia, además sus componentes simbólicos son bajos. El perfil D agrupa aquellas ocupaciones que requieren unos bajos niveles de competencias lingüísticas, ya que únicamente se utilizan en situaciones concretas y a niveles relativamente simples, son ocupaciones que además presentan componentes simbólicos bastante bajos. Finalmente, el grupo E engloba aquellas ocupaciones que requieren muy poco nivel de competencias lingüísticas, el mínimo imprescindible para entender las órdenes de los superiores y coordinarse con sus compañeros/as, y que además prácticamente no requieren de componentes simbólicos.

En definitiva, los grupos A y B engloban aquellas ocupaciones que precisan de personal altamente cualificado, con certificación académica de niveles educativos altos, alto nivel simbólico, capaz de analizar y transmitir información y conocimientos, y que debe tomar decisiones; correspondiéndose, por lo general, con los empleados de "cuello blanco", niveles ejecutivos o administrativos elevados. Por el contrario, en los grupos D y E se encuadran aquellas ocupaciones que desempeñan personal con poca cualificación, sin certificación académica o con niveles de estudios bajos, bajo o nulo nivel simbólico, que son receptores de informaciones, y no toman decisiones; se corresponden, pues, con los empleados de "cuello azul", operarios o mano de obra. De acuerdo con los planteamientos de Sanchis (1989) y Castells (2000), las ocupaciones de los grupos A y B estarían desempeñadas, por lo general, por empleados "insustituibles", mientras que las ocupaciones de los grupos D y E lo estarían por empleados "sustituibles". Por su parte, el grupo $C$ quedaría a mitad camino, en una zona intermedia, entre ambos extremos. Ello pone de manifiesto una relación directa entre status profesional o categoría laboral y requerimientos de competencia lingüística en las ocupaciones de niveles más elevados y más bajos; en el sentido que en los Perfiles A y B se encuadran aquellas ocupaciones que requieren empleados con mayor nivel de formación académica $y$ mayor capacidad de decisión y responsabilidad, es decir que se corresponden con categorías laborales de un elevado status profesional, pero que a la vez requieren más competencias lingüísticas. En cambio, en los perfiles D y E se encuentran aquellas ocupaciones cuyos empleados presentan bajos niveles de formación académica y bajos niveles de decisión y responsabilidad, es decir ocupaciones con bajo status profesional y que requieren escasas competencias lingüísticas. Esta 
correspondencia no se cumple en las ocupaciones de status profesional medio, en donde el nivel de requisitos lingüísticos es más heterogéneo.

Por otro lado, los mapas autoorganizativos de Kohonen se han aplicado a tres de los cuatro niveles de agregación de las ocupaciones que utiliza la clasificación O'Net-SOC-2010ะ a) a las 96 categorías de Grupos Menores (Minor Groups), b) a las 449 categorías al nivel de agrupación Ocupaciones Amplias (Broad Occupations), y c) a las 754 ocupaciones específicas del nivel de agrupación Ocupaciones Detalladas (Detailed Occupations) (de las 821 existentes, recuérdese que se han descartado 67 ocupaciones por no disponer de datos en alguna de las variables utilizadas). Se observa que en algunos casos existen diferencias de clasificación en función del nivel de agregación de las ocupaciones (véase Tabla 5). Ello se debe a dos razones: 1) los mapas autoorganizativos de Kohonen clasifican los patrones (ocupaciones) en grupos en función de la similitud entre ellos, y dependiendo del número de patrones que implica cada nivel de agregación se generan distancias diferentes, y 2) la clasificación de ocupaciones O'Net-SOC-2010 ordena las ocupaciones por familias o ramas de actividad (similitud de las tareas a desempeñar), y no por su similitud en los requerimientos de competencias lingüísticas, motivo por el cual puede ocurrir que ocupaciones que pertenecen a un mismo nivel de agrupación (Grupo Menor, Ocupaciones Amplias o Detalladas) presenten niveles de requerimiento de competencias lingüísticas diferentes, quedando encuadradas en perfiles diferentes.

Es precisamente por ello, que la aportación que se realiza al campo de estudio supone una aproximación metodológica novedosa, al ser la primera vez que se aplican los SOM para la clasificación de las ocupaciones laborales en función de sus similitudes en cuanto a niveles requeridos de competencia lingüística. Esta clasificación puede ser de gran ayuda a los investigadores sociales que analizan el mundo de las ocupaciones laborales, pero se recomienda que se utilice preferentemente la clasificación a nivel de Ocupaciones Detalladas (Detailed).

Evidentemente, la clasificación de ocupaciones obtenida también presenta limitaciones. En primer lugar, dado que se ha efectuado a partir de datos del año 2015 en los EE.UU., se trata de una clasificación válida para dicho contexto temporal y territorial, pero que quizá no sea generalizable a otros países que presenten características políticas, económicas, sociales, culturales y de funcionamiento del mercado de trabajo distintas. Aunque las diferencias serían escasas y únicamente afectarían posiblemente a las ocupaciones que se encuentran en la "frontera" entre dos grupos o perfiles, esta deficiencia es fácilmente subsanable generando una clasificación de ocupaciones utilizando la misma metodología con datos del país en cuestión, siempre que se disponga de datos cuantitativos sobre 
el nivel de requerimientos lingüísticos de las ocupaciones para las variables lingüísticas utilizadas, o en su defecto se lleve a cabo una encuesta con las mismas o parecidas preguntas y metodología que realiza O'Net para obtener los datos.

En segundo lugar, otra limitación de la clasificación es que se basa estrictamente en las ocho variables utilizadas para definir la ocupación en función de sus competencias lingüísticas. No se tienen en cuenta otras dimensiones directamente relacionadas con el lenguaje, como por ejemplo las habilidades de comunicación o el tratamiento de la información, su impacto recíproco con las habilidades técnicas y/o las habilidades cognitivas.

En cualquier caso, la clasificación obtenida, en el contexto geográfico y temporal en el que se enmarca, resulta un instrumento útil para los investigadores/as que deseen analizar la relación entre diversas variables (productividad, empleabilidad, competitividad, etc.) y el nivel lingüístico de las ocupaciones.

\section{Referencias bibliográficas}

Alarcón, Amado; Antonio Di Paolo; Josiah Heyman, y María Cristina Morales (2014). "The occupational location of Spanish-English bilinguals in the new information economy: The health and criminal justice sector in the U.S. borderlands with Mexico". In Callahan, Rebecca M., and Patricia C. Gandara (eds.), The bilingual advantage: Language, literacy, and the U.S. labor market [pp. 110-137]. Tonawanda (NY): Multilingual Matters.

Arвiв, Michael A. (ed.) (2003). The handbook of brain theory and neural networks. London: The MIT Press.

Bueno, Eduardo (1998). "El capital intangible como clave estratégica en la competencia actual." Boletín de Estudios Económicos, 53(2): 207-229.

Bueno, Eduardo (2000). "Una conceptualización integradora de la dirección del conocimiento." Jornada dels Economistes 2000. Barcelona: Collegi d'Economistes de Catalunya.

Castells, Manuel (2000). La era de la información: Economía, sociedad y cultura (Vol. I: La sociedad red). Madrid: Alianza. [Versión original en inglés: The information age: Economy, society, and culture. Vol. I: The rise of the network society. London, Blackwell, 1996].

Chiswick, Barry R., y Paul W. Miller (2010). "Occupational language requirements and the value of English in the United States labor market". Journal of Population Economics, 23(1): 353-372.

Chouliara ki, Lilie, y Norman Fairclough (1999). Discourse in late modernity: Rethinking critical discourse analysis. Edinburgh: Edinburgh University Press. 
Fletcher, Jeannie (2018). "Rapport management". In Vine, Bernadette (ed.), The Routledge handbook of language in the workplace [pp. 77-88]. New York: Roudledge.

Flowerdew, John (2002). "Globalization discourse: A view from the East." Discourse E Society, (13): 209-225.

Gallego, Domingo José; Carlos Ongallo, Óscar Rodríguez, y Raúl de Tena (2003). Conocimiento y gestión: La gestión del conocimiento para la mejora de las personas y las organizaciones. Madrid: Pearson Prentice Hall.

Gordon, Cynthia, y Joshua Kraut (2018). "Interactional sociolinguistics". In Vine, Bernadette (ed.), The Routledge handbook of language in the workplace [pp. 3-14]. New York: Roudledge.

Grin, François; Claudio Sfreddo, y François Vaillancourt (2010). The economics of the multilingual workplace. New York: Roudledge.

Gumperz, John J. (1982a). Discourse strategies. Cambridge: Cambridge University Press.

Gumperz, John J. (ed.) (1982b). Language and social identity. Cambridge: Cambridge University Press.

Heller, Monica (2005). "Language, skill and authenticity in the globalized new economy." Noves SL: Revista de Sociolingüistica, Avalaible to: <http://www. gencat.cat/llengua/noves/noves/hm05hivern/heller1_2.htm >

Idema, Rick, y Hermine Scheeres (2003). "From doing work to talking work: Renegotiating knowing, doing, and identity". Applied Linguistics, (24): 316 337.

Isphording, Ingo E (2014). Language and labor market success. Discussion Paper No. 8572, october. Forschungsinstitut zur Zukunft der Arbeit, IZA (Institute for the Study of Labor), Bonn.

Kim, W. Chan, y Renée Mauborgne (1997). "Fair process: Managing in the knowledge economy." Harvard Business Review, 75(4): 65-75.

Kohonen, Teuvo (1982). "Self-organized formation of topologically correct feature maps." Biological Cybernetics, (43): 59-69.

Kohonen, Teuvo (1988). "An introduction to neural computing." Neural Networks, (1):3-16.

McCulloch, Warren, y Walter Pitт (1943). "A logical calculus of the ideas immanent in nervous activity." Bulletin of Mathematical Biophysics, (5): 115 133.

Nonaka, Ikujiro, y Hirotaka Takeuchi (1995). The knowledge creating company: How Japanese companies create the dynamics of innovation. New York: Oxford University Press. 
Recio, María Luisa (2005). Los recursos intangibles: Gestión y reconocimiento en la empresa española. Madrid: Instituto de Estudios Económicos.

Reich, Robert B. (1991). The work of nations: Preparing ourselves for 21st century capitalism. New York: Knopf.

Rosenblatt, Frank (1958). "The perceptron: A probabilistic model for information storage and organization in the brain." Psychological Review, 65(6): 386-408.

Sanchis, Enric (1989). "Cambio técnico y cualificaciones laborales: Últimas contribuciones a un debate siempre abierto." Sistema: Revista de Ciencias Sociales, (90): 43-64.

Spencer-Oatey, Helen (2008). "Introduction”. In Spencer-Oatey, Helen (ed.), Culturally speaking: Culture, communication and politeness theory [pp. 1-8]. London: Continuum.

Turing, Alan (1937). "On computable numbers, with an application to the entscheidungsproblem." Proceedings of the London Mathematical Society, s242(1): 230-265.

VAn De Mieroop, Dorien, y Jonathan Clifton (2018)."Corporate settings”. In Vine, Bernadette (ed.), The Routledge handbook of language in the workplace [pp. 127-137]. New York: Roudledge. 
ANEXO 1: SOM resultante para el nivel de desagregación Grupos Menores (Minor Groups) (ordenados de menor a mayor nivel de requerimiento de competencias lingüisticas).

\section{Notas:}

- En color azul el grupo de ocupaciones que presentan un muy bajo nivel de exigencia en cuanto a competencias lingüísticas.

+ En color verde el grupo de ocupaciones que presentan un bajo nivel de requerimientos de competencias lingüísticas.

- En color amarillo el grupo de ocupaciones que presentan un nivel intermedio de competencias lingüísticas.

- En color naranja el grupo de ocupaciones que presentan un alto nivel de requerimientos de competencias lingüísticas.

- En color rojo el grupo de ocupaciones que presentan un muy alto nivel de exigencia en cuanto a competencias lingüísticas.

\begin{tabular}{|c|c|c|}
\hline $\begin{array}{l}\text { - Otros trabajadores relacionados con la } \\
\text { preparación y el servicio de alimentos } \\
\text { - Mantenimiento de terrenos } \\
\text { - Asistentes, Vendedores de inmuebles } \\
\text { - Procesamiento de alimentos } \\
\text { - Trabajadores textiles y de la confección } \\
\text { - Trabajadores de material en movimiento }\end{array}$ & $\begin{array}{l}\text { Trabajadores de la } \\
\text { limpieza y el control de } \\
\text { plagas }\end{array}$ & $\begin{array}{l}\text { - Cocineros y preparadores de } \\
\text { alimentos } \\
\text { - Pescadores y cazadores } \\
\text { - Carpinteros }\end{array}$ \\
\hline $\begin{array}{l}\text { - Oficios de la construcción } \\
\text { - Ensambladores y fabricantes } \\
\text { - Trabajadores del metal y el plástico } \\
\text { - Otras ocupaciones de producción }\end{array}$ & - Agricultores & $\begin{array}{l}\text { - Camareros (comida y bebida) } \\
\text { - Asistentes de entretenimiento } \\
\text { - Trabajadores de la apariencia } \\
\text { personal (barberos, peluqueros, } \\
\text { maquilladores, cosmetólogos) }\end{array}$ \\
\hline $\begin{array}{l}\text { - Forestales, conservadores de bosques y } \\
\text { madereros } \\
\text { - Trabajadores extractivos (mineros) }\end{array}$ & - Impresores & $\begin{array}{l}\text { - Instaladores y reparadores de } \\
\text { maquinaria y vehículos }\end{array}$ \\
\hline $\begin{array}{l}\text { - Auxiliares de enfermería y psiquiatría } \\
\text { - Otros trabajadores de la construcción }\end{array}$ & $\begin{array}{l}\text { - Otros trabajadores de la } \\
\text { instalación, mantenimiento } \\
\text { y reparación }\end{array}$ & $\begin{array}{l}\text { - Cuidadores de animales } \\
\text { - Operadores de vehículos } \\
\text { motorizados (camioneros, taxistas) } \\
\text { - Otros transportistas }\end{array}$ \\
\hline $\begin{array}{l}\text { - Instaladores y reparadores de equipos } \\
\text { mecánicos, eléctricos y electrónicos } \\
\text { - Operadores de planta y de sistemas } \\
\text { - Trabajadores de transporte ferroviario }\end{array}$ & & $\begin{array}{l}\text { - Registradores y programadores de } \\
\text { materiales }\end{array}$ \\
\hline $\begin{array}{l}\text { - Otros trabajadores de oficina y auxiliares } \\
\text { administrativos } \\
\text { - Trabajadores del transporte de agua }\end{array}$ & & $\begin{array}{l}\text { - Botones y conserjes, porteadores de } \\
\text { equipajes } \\
\text { - Trabajadores de ventas minoristas } \\
\text { (dependientes) }\end{array}$ \\
\hline - Otras ocupaciones de soporte a la salud & $\begin{array}{l}\text { - Otros trabajadores de } \\
\text { servicios de protección } \\
\text { - Supervisores de cuidados } \\
\text { y servicios personales y } \\
\text { Personal } \\
\text { - Otros trabajadores de } \\
\text { cuidados y servicios } \\
\text { personales } \\
\text { - Empleados financieros }\end{array}$ & \\
\hline $\begin{array}{l}\text { - Auxiliares de terapia ocupacional y } \\
\text { fisioterapeutas } \\
\text { - Supervisores de preparación de } \\
\text { alimentos }\end{array}$ & $\begin{array}{l}\text { - Trabajadores con equipos } \\
\text { de medios de comunicación } \\
\text { (cámaras TV, etc.) }\end{array}$ & $\begin{array}{l}\text { - Otros trabajadores de ventas } \\
\text { - Operadores de equipos de } \\
\text { comunicación }\end{array}$ \\
\hline
\end{tabular}




\begin{tabular}{|c|c|c|}
\hline $\begin{array}{l}\text { - Supervisores de edificios y de } \\
\text { limpiadores y mantenedores de terrenos } \\
\text { - Supervisores de trabajos agrícolas, } \\
\text { pesqueros y forestales } \\
\text { - Supervisores de trabajadores de la } \\
\text { construcción y de la minería } \\
\text { - Supervisores de trabajadores de } \\
\text { producción } \\
\text { - Supervisores de trabajadores del } \\
\text { transporte }\end{array}$ & & $\begin{array}{l}\text { - Artistas y diseñadores } \\
\text { - Trabajadores de funerarias } \\
\text { - Registradores de información }\end{array}$ \\
\hline $\begin{array}{l}\text { - Delineantes, técnicos ingenieros y } \\
\text { cartógrafos } \\
\text { - Tecnólogos y técnicos sanitarios }\end{array}$ & & $\begin{array}{l}\text { - Animadores de espectáculos } \\
\text { - Guías turísticos }\end{array}$ \\
\hline \multirow[t]{2}{*}{$\begin{array}{l}\text { - Informáticos } \\
\text { - Técnicos de las ciencias sociales, ciencias } \\
\text { físicas y de las ciencias de la vida } \\
\text { - Trabajadores para el cumplimiento de la } \\
\text { ley (policías, aduaneros, etc.) }\end{array}$} & - Auxiliares legales & $\begin{array}{l}\text { - Secretariado y asistentes } \\
\text { administrativos }\end{array}$ \\
\hline & & $\begin{array}{l}\text { - Otros educadores e instructores } \\
\text { - Supervisores de trabajadores de } \\
\text { oficina y de soporte administrativo } \\
\text { - Supervisores de trabajadores de } \\
\text { instalación, mantenimiento y } \\
\text { reparación } \\
\text { - Trabajadores de transporte aéreo }\end{array}$ \\
\hline $\begin{array}{l}\text { - Matemáticos } \\
\text { - Bibliotecarios, conservadores y } \\
\text { archiveros } \\
\text { - Bomberos y trabajadores de prevención }\end{array}$ & - Especialistas financieros & $\begin{array}{l}\text { - Maestros de pereescolar, primaria, } \\
\text { secundaria y educación especial } \\
\text { - Supervisores de trabajadores de } \\
\text { ventas } \\
\text { - Representantes de ventas minoristas }\end{array}$ \\
\hline $\begin{array}{l}\text { - Arquitectos, topógrafos y cartógrafos } \\
\text { - Otras ocupaciones de educación y } \\
\text { formación, y bibliotecas }\end{array}$ & & $\begin{array}{l}\text { - Médicos de diagnóstico y tratamiento } \\
\text { - Representantes de ventas mayoristas }\end{array}$ \\
\hline $\begin{array}{l}\text { - Especialistas en operaciones comerciales } \\
\text { - Ingenieros } \\
\text { - Otras ocupaciones de la salud } \\
\text { - Supervisores de trabajadores de serviciso } \\
\text { de protección }\end{array}$ & & $\begin{array}{l}\text { - Asesores, trabajadores sociales y } \\
\text { otros especialsitas en servicios } \\
\text { comunitarios }\end{array}$ \\
\hline $\begin{array}{l}\text { - Directores de producción } \\
\text { - Otras ocupaciones de dirección y gestión }\end{array}$ & $\begin{array}{l}\text { - Alta dirección ejecutiva } \\
\text { - Científicos de ciencias de } \\
\text { la vida } \\
\text { - Físicos }\end{array}$ & $\begin{array}{l}\text { - Directivos de publicidad, marketing, } \\
\text { promociones, relaciones públicas y } \\
\text { ventas } \\
\text { - Científicos sociales } \\
\text { - Trabajadores religiosos (curas) } \\
\text { - Juristas, abogados y jueces } \\
\text { - Profesores universitarios } \\
\text { - Periodistas y empleados de medios de } \\
\text { comunicación }\end{array}$ \\
\hline
\end{tabular}


Anexo 2: Mapas de características del SOM por variables lingüísticas.

Notas:

+ Variable 1: Habilidades orales

+ Variable 2: Habilidades escritas

- Variable 3: Claridad en el discurso

- Variable 4: Reconocimiento del habla

- Variable 5: Conocimiento del inglés

- Variable 6: Habilidad de hablar

- Variable 7: Comunicación con personas ajenas a la organización

- Variable 8: Comunicación con superiores, iguales o subordinados
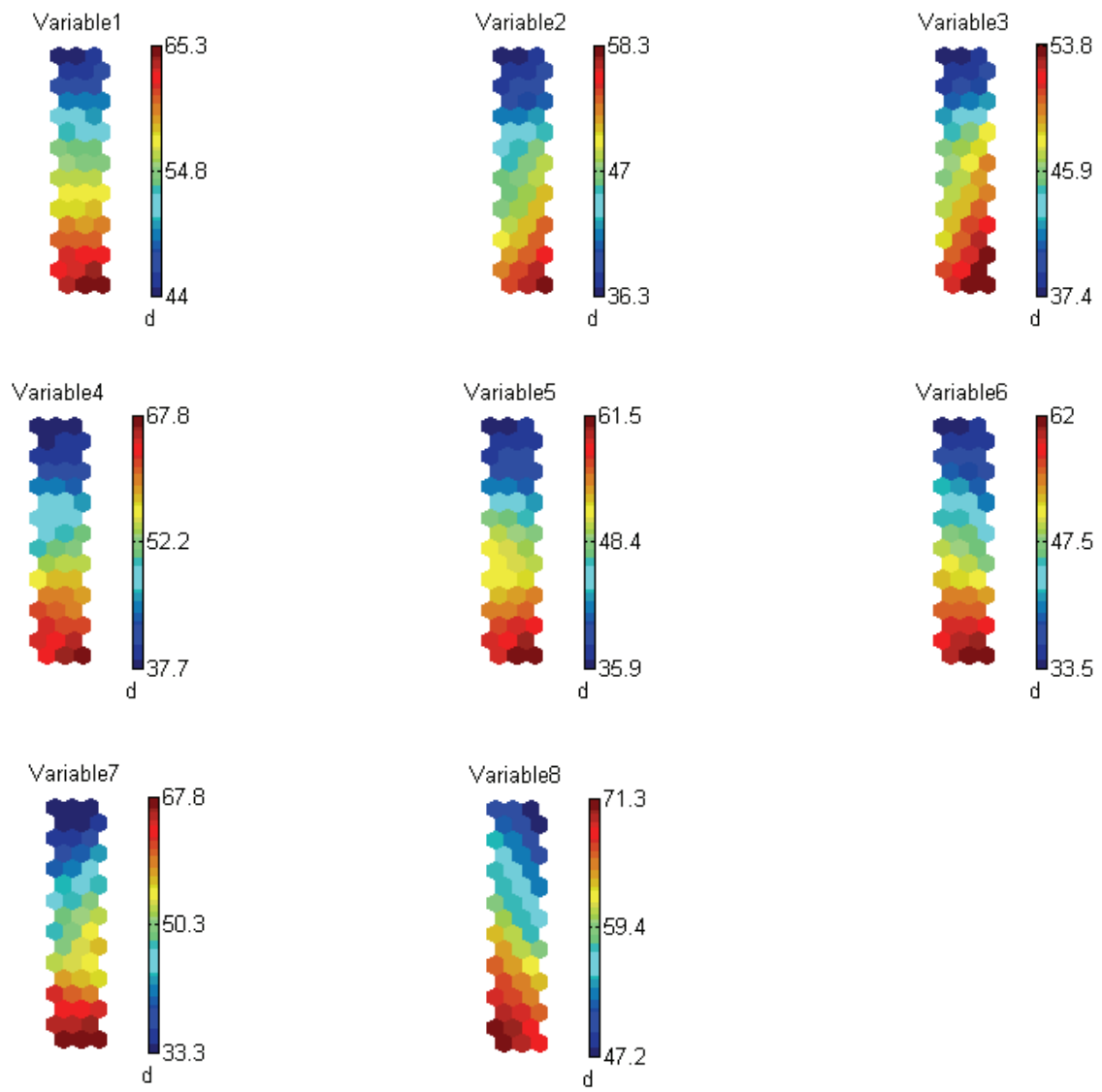
Anexo 3: Clasificación del conjunto de ocupaciones para distintos niveles de desagregación, en cinco grupos en función de los requisitos de competencia lingüistica

(Los códigos que se muestran en este anexo son los que corresponden a la clasificación O'Net-SOC-2010. La ocupación a la que hacen referencia puede consultarse en $<$ https://www.onetcenter.org/taxonomy/2010/list.html>). El código de color indica el perfil al que pertenece cada ocupación siguiendo la escala definida en el Anexo 1 y la Tabla 4.

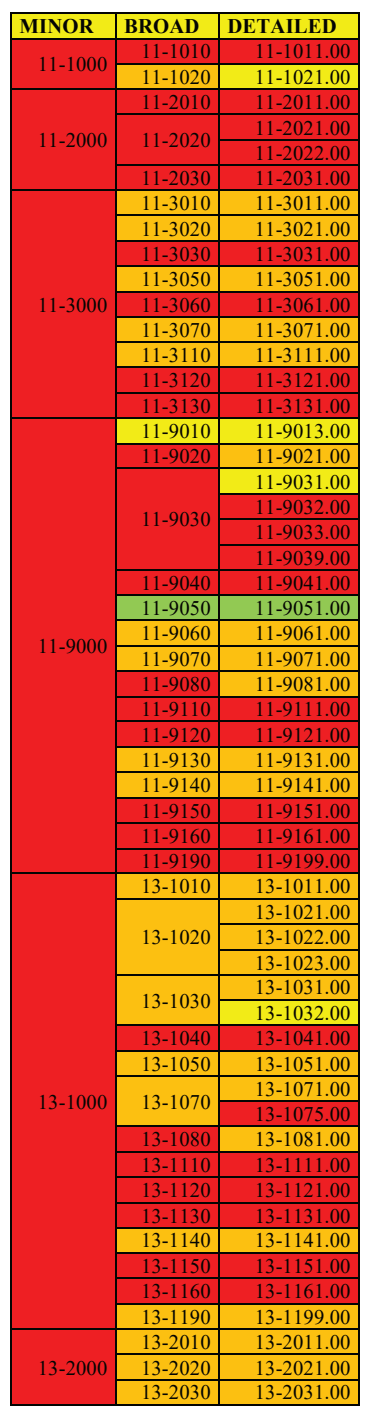

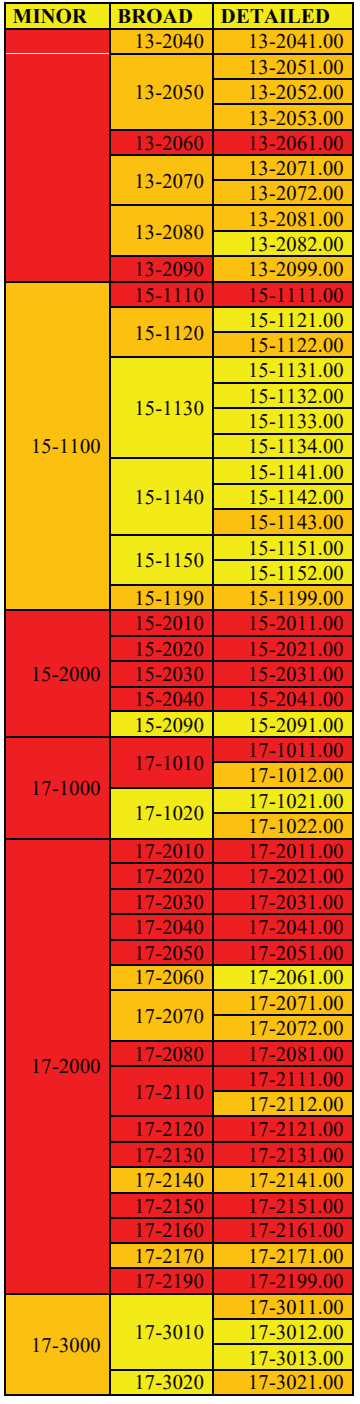

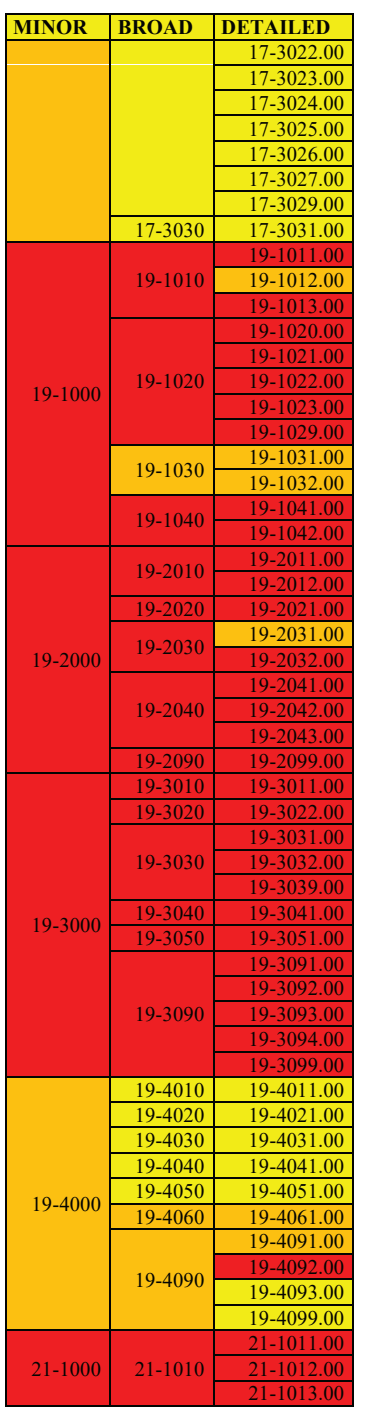




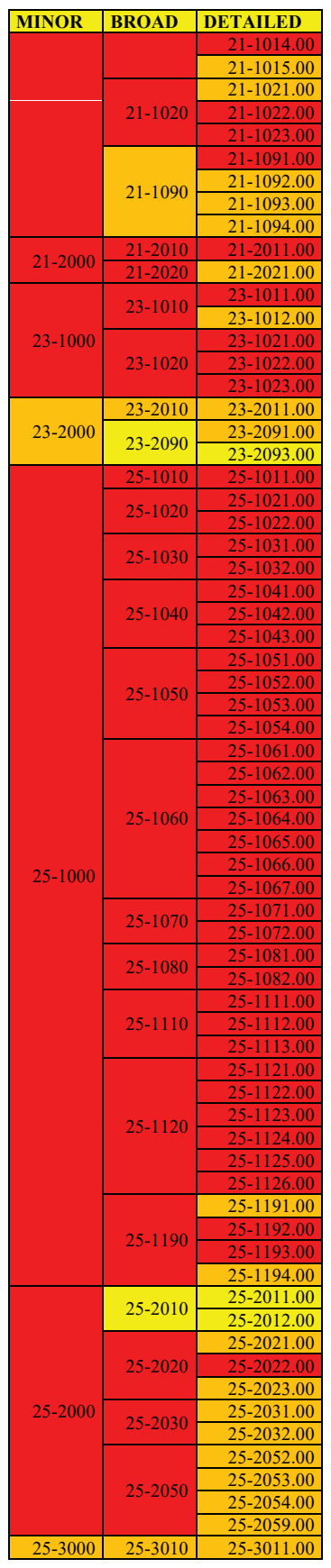

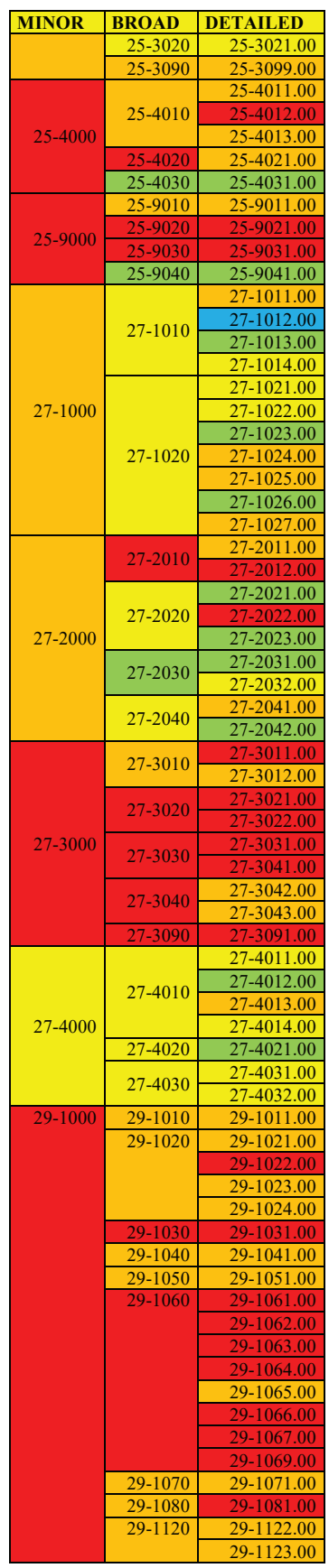




\begin{tabular}{|c|c|c|}
\hline \multirow[t]{3}{*}{ MINOR } & BROAD & DETAILED \\
\hline & \multirow[t]{2}{*}{$33-3050$} & $33-3051.00$ \\
\hline & & $33-3052.00$ \\
\hline \multirow[t]{8}{*}{$33-9000$} & $33-9010$ & $33-9011.00$ \\
\hline & $33-9020$ & $33-9021.00$ \\
\hline & \multirow[t]{2}{*}{$33-9030$} & $33-9031.00$ \\
\hline & & $33-9032.00$ \\
\hline & \multirow{4}{*}{$33-9090$} & $33-9091.00$ \\
\hline & & $33-9092.00$ \\
\hline & & $33-9093.00$ \\
\hline & & $33-9099.00$ \\
\hline \multirow[t]{2}{*}{$35-1000$} & \multirow[t]{2}{*}{$35-1010$} & $35-1011.00$ \\
\hline & & $35-1012.00$ \\
\hline \multirow{6}{*}{$35-2000$} & \multirow[t]{5}{*}{$35-2010$} & $35-2011.00$ \\
\hline & & $35-2012.00$ \\
\hline & & $35-2013.00$ \\
\hline & & $35-2014.00$ \\
\hline & & $35-2015.00$ \\
\hline & $35-2020$ & $35-2021.00$ \\
\hline \multirow[t]{5}{*}{$35-3000$} & $35-3010$ & $35-3011.00$ \\
\hline & \multirow[t]{2}{*}{$35-3020$} & $35-3021.00$ \\
\hline & & $35-3022.00$ \\
\hline & $35-3030$ & $35-3031.00$ \\
\hline & $35-3040$ & $35-3041.00$ \\
\hline \multirow[t]{3}{*}{$35-9000$} & $35-9010$ & $35-9011.00$ \\
\hline & $35-9020$ & $35-9021.00$ \\
\hline & $35-9030$ & $35-9031.00$ \\
\hline \multirow[t]{2}{*}{$37-1000$} & \multirow[t]{2}{*}{$37-1010$} & $37-1011.00$ \\
\hline & & $37-1012.00$ \\
\hline $37-2000$ & $37-2010$ & $37-2011.00$ \\
\hline & & $37-2012.00$ \\
\hline & $37-2020$ & $37-2021.00$ \\
\hline $37-3000$ & $37-3010$ & $37-3011.00$ \\
\hline & & $37-3012.00$ \\
\hline & & $37-3013.00$ \\
\hline $39-1000$ & $39-1010$ & $39-1011.00$ \\
\hline & & $39-1012.00$ \\
\hline & $39-1020$ & $39-1021.00$ \\
\hline $39-2000$ & $39-2010$ & $39-2011.00$ \\
\hline & $39-2020$ & $39-2021.00$ \\
\hline $39-3000$ & $39-3010$ & $39-3011.00$ \\
\hline & & $39-3012.00$ \\
\hline & $39-3020$ & $39-3021.00$ \\
\hline & 39-3030 & $39-3031.00$ \\
\hline & $39-3090$ & $39-3091.00$ \\
\hline & & $39-3092.00$ \\
\hline & & $39-3093.00$ \\
\hline $39-4000$ & $39-4010$ & $39-4011.00$ \\
\hline & $39-4020$ & $39-4021.00$ \\
\hline & $30-4030$ & $39-4031.00$ \\
\hline $39-5000$ & $39-5010$ & $39-5011.00$ \\
\hline & & $39-5012.00$ \\
\hline & $39-5090$ & $39-5091.00$ \\
\hline & & $39-5093.00$ \\
\hline & & $39-5094.00$ \\
\hline $39-6000$ & $39-6010$ & $39-6011.00$ \\
\hline & & $39-6012.00$ \\
\hline $39-7000$ & $39-7010$ & $39-7011.00$ \\
\hline & & $39-7012.00$ \\
\hline $39-9000$ & $39-9010$ & $39-9011.00$ \\
\hline & $39-9020$ & $39-9021.00$ \\
\hline & $39-9030$ & $39-9031.00$ \\
\hline & & $39-9032.00$ \\
\hline & $39-9040$ & $39-9041.00$ \\
\hline $41-1000$ & 41-1010 & $41-1011.00$ \\
\hline & & $41-1012.00$ \\
\hline $41-2000$ & $41-2010$ & $41-2011.00$ \\
\hline & & $41-2012.00$ \\
\hline
\end{tabular}

\begin{tabular}{|c|c|c|}
\hline \multirow[t]{4}{*}{ MINOR } & BROAD & DETAILED \\
\hline & \multirow[t]{2}{*}{$41-2020$} & $41-2021.00$ \\
\hline & & $41-2022.00$ \\
\hline & 41-2030 & $41-2031.00$ \\
\hline \multirow[t]{5}{*}{$41-3000$} & $41-3010$ & $41-3011.00$ \\
\hline & $41-3020$ & $41-3021.00$ \\
\hline & $41-3030$ & $41-3031.00$ \\
\hline & $41-3040$ & $41-3041.00$ \\
\hline & $41-3090$ & $41-3099.00$ \\
\hline \multirow[t]{2}{*}{$41-4000$} & \multirow[t]{2}{*}{$41-4010$} & $41-4011.00$ \\
\hline & & $41-4012.00$ \\
\hline \multirow[t]{7}{*}{$41-9000$} & \multirow[t]{2}{*}{$41-9010$} & $41-9011.00$ \\
\hline & & $41-9012.00$ \\
\hline & \multirow[t]{2}{*}{$41-9020$} & $41-9021.00$ \\
\hline & & $41-9022.00$ \\
\hline & $41-9030$ & $41-9031.00$ \\
\hline & $41-9040$ & $41-9041.00$ \\
\hline & $41-9090$ & $41-9091.00$ \\
\hline $43-1000$ & 43-1010 & $43-1011.00$ \\
\hline \multirow[t]{2}{*}{$43-2000$} & $43-2010$ & $43-2011.00$ \\
\hline & $43-2020$ & $43-2021.00$ \\
\hline \multirow[t]{7}{*}{$43-3000$} & $43-3010$ & $43-3011.00$ \\
\hline & $43-3020$ & $43-3021.00$ \\
\hline & $43-3030$ & $43-3031.00$ \\
\hline & $43-3040$ & $43-3041.00$ \\
\hline & 43-3050 & $43-3051.00$ \\
\hline & $43-3060$ & $43-3061.00$ \\
\hline & $43-3070$ & $43-3071.00$ \\
\hline \multirow[t]{16}{*}{$43-4000$} & $43-4010$ & $43-4011.00$ \\
\hline & $43-4020$ & $43-4021.00$ \\
\hline & $43-4030$ & $43-4031.00$ \\
\hline & $43-4040$ & $43-4041.00$ \\
\hline & 43-4050 & $43-4051.00$ \\
\hline & $43-4060$ & $43-4061.00$ \\
\hline & $43-4070$ & $43-4071.00$ \\
\hline & $43-4080$ & $43-4081.00$ \\
\hline & $43-4110$ & $43-4111.00$ \\
\hline & $43-4120$ & $43-4121.00$ \\
\hline & $43-4130$ & $43-4131.00$ \\
\hline & $43-4140$ & $43-4141.00$ \\
\hline & $43-4150$ & $43-4151.00$ \\
\hline & $43-4160$ & $43-4161.00$ \\
\hline & $43-4170$ & $43-4171.00$ \\
\hline & $43-4180$ & $43-4181.00$ \\
\hline \multirow[t]{12}{*}{$43-5000$} & $43-5010$ & $43-5011.00$ \\
\hline & $43-5020$ & $43-5021.00$ \\
\hline & \multirow[t]{2}{*}{$43-5030$} & $43-5031.00$ \\
\hline & & $43-5032.00$ \\
\hline & $43-5040$ & $43-5041.00$ \\
\hline & \multirow[t]{3}{*}{$43-5050$} & $43-5051.00$ \\
\hline & & $43-5052.00$ \\
\hline & & $43-5053.00$ \\
\hline & $43-5060$ & $43-5061.00$ \\
\hline & $43-5070$ & $43-5071.00$ \\
\hline & $43-5080$ & $43-5081.00$ \\
\hline & $43-5110$ & $43-5111.00$ \\
\hline $43-6000$ & $43-6010$ & $43-6011.00$ \\
\hline & & $43-6012.00$ \\
\hline & & $43-6013.00$ \\
\hline & & $43-6014.00$ \\
\hline $43-9000$ & $43-9010$ & $43-9011.00$ \\
\hline & $43-9020$ & $43-9022.00$ \\
\hline & $43-9030$ & $43-9031.00$ \\
\hline & $43-9040$ & $43-9041.00$ \\
\hline & $43-9050$ & $43-9051.00$ \\
\hline & $43-9060$ & $43-9061.00$ \\
\hline & $43-9070$ & $43-9071.00$ \\
\hline & $43-9080$ & $43-9081.00$ \\
\hline
\end{tabular}




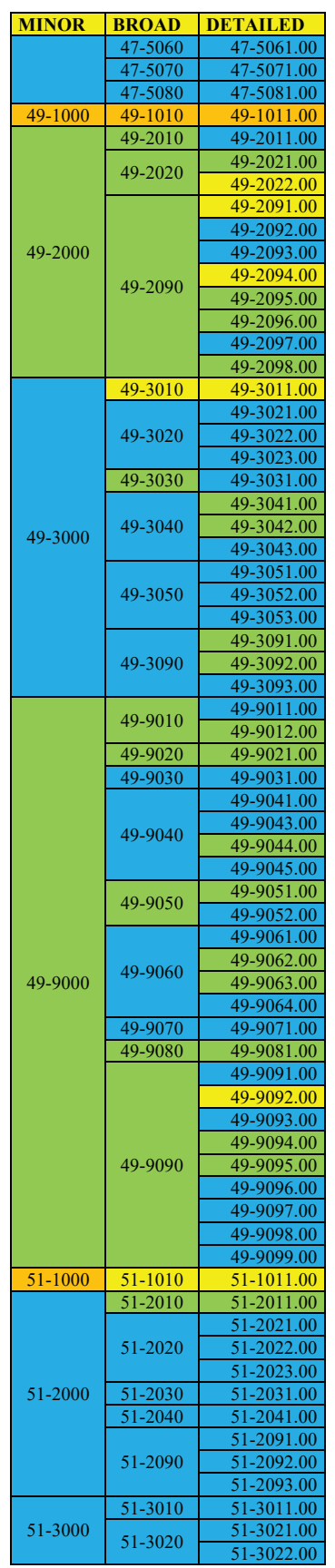

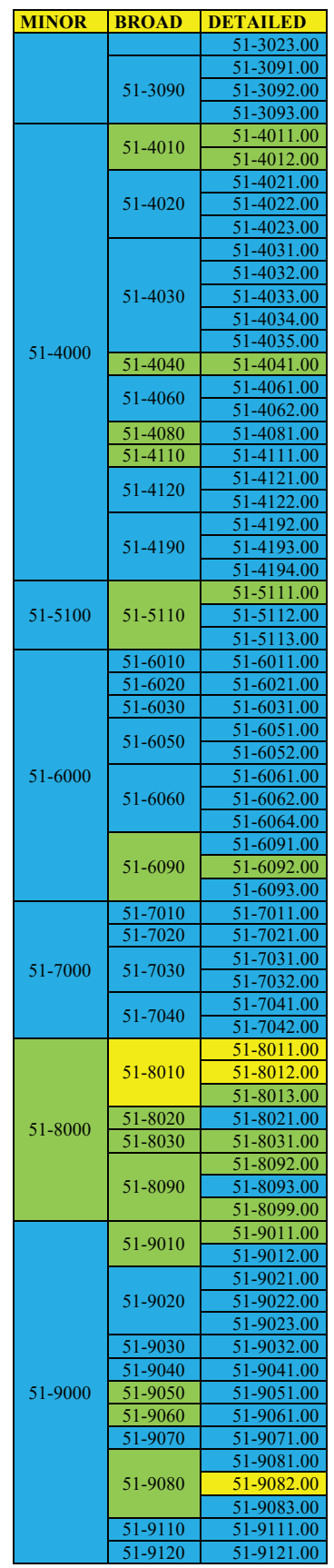

